\title{
A INVISIBILIDADE DA CRIANÇA IMIGRANTE NO ATENDIMENTO EDUCATIVO DA REDE PÚBLICA DE ENSINO DE PONTA GROSSA/PR
}

\author{
Marilúcia AntônIa de ReSende Peroza \\ Natália MENDES dos SANTOS \\ Universidade Estadual de Ponta Grossa (UEPG), Ponta Grossa, Paraná, Brasil
}

\begin{abstract}
Resumo: No interior dos fluxos migratórios, as crianças constituem um dos grupos mais vulneráveis às violações de direitos e com menor visibilidade para sua condição nos deslocamentos. Com o aumento da imigração no Brasil, constatou-se, também, um número significativo de crianças imigrantes na rede pública de ensino de Ponta Grossa/PR, o que desencadeou a realização do estudo cujos resultados parciais trazemos neste texto. O objetivo deste artigo é apresentar uma análise sobre a invisibilidade das crianças imigrantes e seus reflexos no atendimento educacional na referida rede de ensino. A pesquisa qualitativa teve como estratégias metodológicas o questionário e a entrevista semiestruturada. $O$ estudo conclui que a invisibilidade das crianças se evidencia nas práticas pedagógicas desenvolvidas na escola.
\end{abstract}

Palavras-chave: Criança Imigrante. Educação. Prática Pedagógica. Invisibilidade.

INTRODUÇÃO

Este artigo tem por objetivo apresentar uma análise sobre a invisibilidade da criança imigrante nas propostas educativas desenvolvidas nas escolas da rede municipal de ensino de Ponta Grossa/PR. Os estudos que estamos desenvolvendo nos levam a entender que a invisibilidade percebida nos dados presentes em relatórios apresentados por organismos nacionais e internacionais, assim como nas pesquisas, são indicativos de que o direito de acesso à educação e a outros serviços de proteção pode estar sendo violado. Aqui, entendemos que o acesso à educação vai além da matrícula, envolvendo, sobretudo, a garantia do direito de aprendizagem, do pleno desenvolvimento e de apropriação cultural baseada no respeito à diversidade.

Tomamos como foco do estudo as crianças imigrantes que, advindas de outros países, se fixam no município com suas famílias e se inserem na rede pública de ensino. Com o intuito de possibilitar um caminho de análise, vamos delinear como os movimentos migratórios têm se constituído no mundo e apresentar alguns dados sobre a imigração no Brasil de modo a nos oferecer um panorama sobre os elementos que nos permitem analisar os dados coletados no município, que estão apresentados de forma mais detalhada nos tópicos 2 e 4 deste trabalho. Também abordamos, brevemente, alguns conceitos que vêm embasando nossas reflexões.

Para nos referirmos à invisibilidade das crianças imigrantes na rede pública de ensino do município, tomamos como pressuposto uma série de evidências que foi 
sendo percebida ao longo do desenvolvimento da pesquisa, como, por exemplo, inicialmente, pelo fato de a secretaria não ter dados sobre a presença dessas crianças na rede para nos apresentar. Posteriormente, nos questionários e entrevistas, ficam latentes a ausência dessa temática na formação proposta pela rede; a falta de um acompanhamento pedagógico por parte da área técnica da secretaria para dar suporte às escolas; a necessidade de uma articulação intersetorial que favoreça o atendimento das crianças e suas famílias, de modo a promover a inserção na cultura local e o acesso aos direitos básicos; e, especificamente, no âmbito das escolas, os desafios vivenciados por professores e equipes pedagógicas no desenvolvimento de suas práticas pedagógicas, muitas vezes, realizadas sem considerar as necessidades das crianças imigrantes. Em 2019, a rede municipal de ensino atendia a 32 crianças imigrantes, advindas de 11 países, em sua maioria latino-americanos, matriculadas em 19 escolas - 4 de Educação Infantil e 15 de Ensino Fundamental. Participaram da pesquisa 13 profissionais, entre professores, coordenador pedagógico e diretores, sendo que 11 responderam a um questionário online e 2 participaram de entrevista semiestruturada, cujas análises apresentaremos posteriormente neste trabalho.

Para iniciarmos essa discussão, cumpre afirmar que os fluxos migratórios internacionais, ainda que estejam presentes como uma dinâmica humana milenar, são um fenômeno que, ao longo da história, têm variado seus motivos e sua intensidade (MILESI, 2005; CASTRO, 2008; CAVALCANTI et al, 2017). Nos últimos anos, a discussão sobre o tema tem ganhado visibilidade devido a acontecimentos como guerras, desastres naturais, perseguições religiosas, dentre outros, bem como pelas políticas de segurança nacional com fechamento de fronteiras e restrições da entrada de imigrantes em alguns países. Esse movimento trouxe discussões, principalmente nos países europeus e na América do Norte, sobre aspectos relacionados à acolhida de milhões de pessoas em trânsito no mundo e seus impactos econômicos, sociais, culturais e políticos (FELDMAN-BIANCO, 2015).

No que se refere ao conceito de migração, não existe consenso para sua definição. Porém, pode-se dizer que há uma convergência para considerar a migração internacional, de acordo com a Organização Internacional para as Migrações (OIM), como o ato de mudar para outro país que não seja o de nacionalidade ou residência, ou seja, a mudança para um país de destino, que se torne efetivamente sua residência habitual. Neste trabalho, trataremos das crianças imigrantes, ou seja, daquelas que se instalam no município de Ponta Grossa advindas de outros países.

Para pensar esses sujeitos em processo de migração, partimos do pressuposto de que se, em sua complexidade, as migrações deixam antever os dramas de milhares de pessoas em deslocamentos, elas encobrem, em suas leituras mais amplas, a presença frágil da criança e das vulnerabilidades que envolvem a vivência de sua infância, esteja ela acompanhada de sua família ou nos trajetos que muitas vezes empreende sozinha.

Isso se evidencia, em certa medida, nos diferentes relatórios sobre imigrações divulgados pelos organismos oficiais nacionais e internacionais (OIM, 2020; OBMIGRA, 2020; ACNUR, 2019, et al.), nos quais encontramos poucos dados sobre as crianças, para além da faixa etária. Em nossa compreensão, a ausência de informações e dados sobre 
PEROZA, M. A. de R.; SANTOS, N. M. dos.

como vivem essas crianças dificulta a formulação de políticas públicas que as protejam e garantam o acesso aos serviços básicos de assistência, educação, saúde, dentre outros.

Nos movimentos migratórios internacionais, boa parte das crianças realizam seus deslocamentos acompanhadas da família e com documentação autorizada (OIM, 2020 , p. 253). No entanto, tornam-se cada vez mais preocupantes as situações em que esse deslocamento está associado à vulnerabilidade, em que as crianças empreendem as travessias sozinhas ou que, junto com suas famílias, enfrentam fome, violências, riscos e inseguranças (COLARES, 2019). Assim, destacamos que uma das dificuldades em reconhecer as situações de violação de direitos e a vulnerabilidade infantil nos deslocamentos se deve à falta de clareza e de definições sobre a migração infantil, bem como a imprecisão dos dados sobre essas crianças.

A preocupação em relação à escassez de fontes confiáveis, que apresentem dados mais precisos e atualizados sobre a migração infantil, é descrita no relatório da OIM (2020). Com base nas estimativas mais recentes, esse relatório afirma existir cerca de 31 milhões de crianças migrantes no mundo, sendo que, destas, cerca de 13 milhões são crianças refugiadas, 936.000 são solicitantes de asilo e 17 milhões são obrigadas a se deslocar dentro de seus países. $O$ relatório citado afirma que, ainda que esta estimativa revele a amplitude do fenômeno, sua exatidão é questionada e seu uso é limitado, pois não indicam em quais países estão, a situação jurídica que as ampara, dentre outros fatores.

Nesse cenário de mobilidade internacional, embora no Brasil seja identificado um número pequeno de crianças, cerca de $4 \%$ no conjunto de imigrantes, os dados apontam que, no mundo, cerca de metade dessa população é formada por crianças e jovens até 18 anos, mas não são apresentadas informações que indiquem, por exemplo, as condições de acesso aos serviços públicos necessários à garantia dos direitos essenciais. Como podemos observar, o relatório da ACNUR (2019), ao analisar o perfil socioeconômico dos refugiados no Brasil, aponta que "os menores de idade foram, por definição, excluídos de nossa amostra" e, na nota de rodapé acrescenta: "não obstante isso, na base de dados da PF/CONARE constam um bom número de menores de idade, como teremos a ocasião de comentar em trabalho futuro" (ACNUR, 2019, p. 9).

Uma constatação a respeito dos relatórios é que, ainda que haja dados, estes, muitas vezes, não apresentam detalhes precisos sobre o acesso das crianças imigrantes à educação, serviços de saúde, proteção, alimentação e moradia, de modo que se possa ter elementos para a elaboração de políticas públicas de atendimento a essa população. Um exemplo disso pode ser encontrado no Relatório do Observatório das Migrações Internacionais (OBMigra), que traz dados sobre o acesso de imigrantes ao ensino regular. Em relação à Educação Infantil, aponta que cerca de 108,8 mil matrículas foram realizadas entre os anos de 2010 e 2019 (CAVALCANTI et al., 2020, p. 2014), no entanto, destaca a importância do acesso das crianças a essa etapa da educação, por um lado, porque é o início da fase de socialização das crianças e possibilita seu desenvolvimento global; e, por outro, porque favorece que as famílias disponham de tempo para o trabalho. Nessa abordagem, fica expresso que o acesso ao direito à educação atende, de algum modo, às necessidades dos adultos, no caso, para que possam trabalhar.

Do mesmo modo que as crianças imigrantes são pouco consideradas nas estatísticas, percebe-se que elas pouco aparecem nas pesquisas que se referem ao tema. Em uma revisão de literatura realizada no início da pesquisa, por meio da plataforma de periódicos da CAPES (Coordenação de Aperfeiçoamento de Pessoal de Nível Superior), 
fizemos uma busca a partir dos descritores: imigrante, refugiado, criança e educação, posicionando as palavras de formas diferentes entre uma busca e outra, a fim de obter os dados. Foram selecionados artigos referentes ao período de 2012 a 2018, todos em língua portuguesa. A partir desses filtros, foram encontrados 80 trabalhos. Na análise dos materiais selecionados, apenas três tratavam da educação e do processo educativo da criança migrante (MACHADO, 2017; TEIXEIRA, 2018; GRAJZER, 2018). Isso evidencia a escassez de publicações que abordam a criança nos fluxos migratórios, assim como dos estudos que as consideram como participantes ativas. Nessa busca, ficou evidente, também, que as pesquisas priorizam os aspectos laborais, os impactos econômicos e políticos dos deslocamentos, as questões relativas a gênero, dignidade humana, dentre outros, com enfoque no adulto migrante (RIFIOTIS, 2018; OLIVEIRA; KÖHLER, 2019).

A partir dessa leitura mais ampla do fenômeno das migrações, além da condição da criança, é possível analisar que, nas políticas educacionais brasileiras, embora a legislação de proteção ao imigrante (BRASIL, 2017) indique o acesso aos serviços públicos em condição de igualdade com os nacionais, na proposta educativa do município de Ponta Grossa não encontramos mecanismos de garantia de acesso a esses direitos expressos em propostas com metas e objetivos claros para a realização de um acompanhamento específico da criança na condição de imigrante e de suas escolas.

Dessa forma, entendemos que as lacunas expressas nos dados estatísticos, nas pesquisas e nas políticas educacionais do município, acabam por evidenciar o que aqui tratamos como invisibilidade da criança imigrante. Por invisibilidade, compreendemos o não-reconhecimento da criança imigrante enquanto um Outro social, constituindo-se como uma atitude produzida culturalmente e que gera um sentimento de indiferença por aquele cuja presença se torna insignificante (TOMÁS, 2008).

Com base nessas evidências, apresentamos os dados parciais de uma pesquisa ${ }^{2}$ que buscou conhecer e caracterizar as crianças imigrantes matriculadas na rede municipal de ensino de Ponta Grossa/PR, além dos desafios enfrentados por professores e equipes pedagógicas no atendimento às especificidades dessas crianças.

$\mathrm{O}$ texto está organizado em quatro tópicos. $\mathrm{Na}$ introdução, traçamos um panorama sobre a discussão aqui apresentada; em seguida, apresentamos a caracterização do estudo em seus procedimentos metodológicos e etapas de organização; no terceiro tópico, elencamos, brevemente, os conceitos e concepções que orientaram nossas análises. Por fim, apresentamos algumas considerações sobre os processos de invisibilização da criança imigrante nos contextos educativos da rede municipal de ensino a partir dos dados obtidos por meio dos questionários e entrevistas.

\section{CARACTERIZAÇÃO DO ESTUDO}

O estudo toma como referência a pesquisa qualitativa, além de envolver o levantamento de dados sobre a presença das crianças imigrantes na rede pública de ensino de Ponta Grossa/PR, cujos resultados foram informados pela Secretaria Municipal de Ensino (SME), em 2019. Esses dados nos indicaram que, naquele momento, 32 crianças imigrantes eram atendidas na rede e estavam matriculadas em 19 escolas de 
PEROZA, M. A. de R.; SANTOS, N. M. dos.

Educação Infantil e nos anos iniciais do Ensino Fundamental. O quadro 1 apresenta o número de crianças e os países de origem:

Quadro1: Número de crianças imigrantes por países de origem

\begin{tabular}{|c|c|}
\hline Nacionalidade & No de crianças \\
\hline Venezuela & 13 \\
\hline Japão & 3 \\
\hline Bangaladesh & 3 \\
\hline Colômbia & 3 \\
\hline Estados Unidos & 2 \\
\hline Haiti & 2 \\
\hline Bolívia & 2 \\
\hline Cuba & 1 \\
\hline Paraguai & 1 \\
\hline Irã & 1 \\
\hline Itália & 1 \\
\hline
\end{tabular}

Fonte: Dados da Secretaria Municipal de Educação de Ponta Grossa (2019).

Identificadas as escolas e as crianças imigrantes matriculadas na rede, foi estabelecido contato com as instituições. Inicialmente, a perspectiva era de inserção no ambiente escolar a partir de março de 2020 para a realização de diálogos e entrevistas com profissionais das escolas que atendiam as crianças imigrantes. No entanto, devido ao contexto de pandemia, passamos a utilizar como instrumentos o questionário enviado por e-mail, para as 19 escolas municipais que atendiam crianças imigrantes, via Google Forms, e a entrevista semiestruturada, por vídeo chamada.

Participaram da pesquisa, ao longo de 2020, 13 profissionais, de diferentes escolas da rede municipal, sendo que 11 responderam ao questionário e 2 participaram das entrevistas. Na elaboração do questionário, buscamos traçar um perfil dos profissionais (3 diretores, 7 professores, e 1 coordenadora pedagógica). Na elaboração do questionário, consideramos as categorias: informações pessoais (formação, tempo de trabalho na educação); as concepções sobre criança e infância; relações com as famílias; desafios vivenciados na prática pedagógica; estratégias pedagógicas no trabalho com as crianças imigrantes; e acompanhamento pedagógico. Para a entrevista semiestruturada, foi elaborado um roteiro, cujas questões consistiam no aprofundamento dos aspectos destacados no questionário.

Vale ressaltar que os procedimentos de investigação foram, em certa medida, modificados devido ao contexto de pandemia vivenciado em 2020, com a suspensão das atividades presenciais nas escolas. No entanto, ao propormos o questionário e as entrevistas, conseguimos manter uma aproximação com o contexto desses profissionais com vistas a um futuro encontro com suas realidades.

\section{BREVE CONTEXTUALIZAÇÃO DE CONCEITOS E CONCEPÇÕES QUE FUNDAMENTAM A ANÁLISE}

As concepções, percepções e práticas sociais em relação à criança e à compreensão da infância enquanto categoria geracional e social, vêm sendo construídas ao longo do tempo, como reflexo das mudanças estruturais da sociedade em seus 
aspectos sociais, políticos, econômicos e culturais (CAMBI, 1999; SARMENTO, 2013; KRAMER; LEITE, 2015).

Do adulto em miniatura (ARIĖS, 2011), passando pela percepção de suas especificidades (ROUSSEAU, 2014), até a compreensão da criança como sujeito de direitos, esboça-se uma trajetória de lutas e buscas de educadores, intelectuais e pesquisadores das diferentes áreas do conhecimento, pelo reconhecimento da dignidade humana da criança e do seu direito a uma infância respeitosa (DALLARI; KORCZAK, 1986). Nesse caminho, a criança, aos poucos, foi saindo do anonimato social, do lugar de quem não tem voz, sentido etimológico da palavra infância, para a máxima expressão de sua condição humana, de autonomia e participação (SOARES, 2005).

No entanto, se, a partir dos regulamentos internacionais e no interior dos diversos países signatários da Convenção sobre os Direitos da Criança (ONU, 1989), ela alcança o status de sujeito de direitos, no cotidiano, as práticas direcionadas à criança ainda demonstram um lugar social menos legítimo em relação aos adultos. Como afirma Sarmento (2013, p. 17),

\begin{abstract}
Nunca como atualmente foram tão alargadamente proclamados os direitos da criança, e nunca como hoje se assistiu a uma tão severa restrição nas condições sociais da infância, especialmente das crianças dos países mais pobres e dos grupos sociais mais empobrecidos dos países ricos, marcadas por situações como o tráfico de crianças, a exploração infantil em unidades industriais e sweatshops, por pandemias como a AIDS, pela fome, pela guerra, pela exposição a catástrofes decorrentes da degradação ambiental, pelo tráfico de crianças, pela violência urbana.
\end{abstract}

Com base nas discussões estabelecidas pelos autores acima citados e outros tantos que têm contribuído para pensarmos a infância, podemos considerar que as concepções acerca da criança se constituem na relação entre os discursos e as práticas e se evidenciam nas políticas públicas que orientam e concretizam as relações sociais vivenciadas no cotidiano. De acordo com Peroza $(2018$, p. 2), "a distância entre os discursos e as práticas no que se refere às relações entre adultos e crianças no processo educativo levanta questões que colocam em xeque toda a construção conceitual dos últimos séculos e, de modo especial, nas últimas décadas".

Partindo da compreensão de que as crianças e os diversos modos de vivenciar suas infâncias estão se constituindo nas relações estabelecidas socialmente, localizamos as crianças, aqui adjetivadas como imigrantes, considerando-as como partícipes dos enredos que envolvem sua vida, embora seus deslocamentos requeiram, muitas vezes, uma adesão involuntária. Peroza $(2018$, p. 17) afirma que

Toda ação da criança é um ato de participação. Ao agir sobre o mundo, sobre si mesma, a criança cria, recria e produz cultura. Não é um ser passivo que acumula conhecimentos para, em dado momento da vida, colocá-los em prática. Antes, ela se apropria, reinventa, produz, reproduz, participa. É na atividade coletiva e 
PEROZA, M. A. de R.; SANTOS, N. M. dos.

conjunta com outras crianças, com os adultos e com os instrumentos simbólicos, que a criança cria a si mesma.

Para considerar a criança imigrante em sua tarefa de constituir-se em uma outra cultura, que não a de origem, torna-se necessário olhar o fenômeno da migração em seus múltiplos aspectos para além dos motivos que levam milhares de pessoas a deixarem sua terra natal em busca de segurança, trabalho, oportunidade de uma nova vida, mas que, muitas vezes, no caminho, perdem a dignidade e os direitos básicos de existência.

Assim, ao tratarmos da criança imigrante, delineamos um contexto social no qual ela e sua família são acolhidas e acabamos por desvelar processos de exclusão e marginalização, expressas nas dificuldades de acesso aos serviços sociais públicos básicos, nos obstáculos impostos pelo não domínio da língua, na luta por conseguir trabalho, e tantos outros.

Nesse cenário, compreendemos que o próprio contexto social se encarrega de manter um estado de exclusão que, na perspectiva de Martins (2002, p. 15), impõe "formas de diferenciação social que imputam a determinadas pessoas lugares sociais não participativos, excludentes, como se elas não pertencessem ao mesmo gênero humano das demais". A sociedade capitalista, ainda que fundamentada em um discurso de igualdade e de direitos, elege modos de constituição das relações que gera a exclusão de pessoas e grupos naturalizados social e culturalmente. Assim, o autor define a exclusão como

um problema social porque abrange a todos: a uns porque os priva do básico para viver com dignidade, como cidadãos; a outros porque lhes impõe o terror da incerteza quanto ao próprio destino e ao destino dos filhos e dos próximos. A verdadeira exclusão está na desumanização própria da sociedade contemporânea, que ou nos torna panfletários na mentalidade ou nos torna indiferentes em relação aos seus indícios visíveis no sorriso pálido dos que não têm um teto, não têm trabalho e, sobretudo, não têm esperança (MARTINS, 2002, p. 21).

Para o autor, o desafio que temos pela frente é o de "compreender que os mecanismos de diferenciação social de classes, que seriam próprios da sociedade contemporânea, foram diversificados e complementados por formas excludentes de diferenciação" (MARTINS, 2002, p. 25).

Tomando como base a definição de Martins (2002), entendemos que, socialmente, temos vários grupos excluídos dos sistemas de produção, de participação, de acesso às condições básicas de existência e de dignidade, fruto de um sistema que produz a exclusão e culturalmente a naturaliza, de modo que perpasse as relações entre os indivíduos de forma transversal.

Nesse sentido, compreendemos que a exclusão é um dos elementos que fundamentam os processos de invisibilização de indivíduos e/ou de grupos, por entender que, nos processos de exclusão, há uma relação entre sujeitos, em que existe o reconhecimento dos excluídos, portanto, são "visíveis" na condição concreta em que se encontram, pois há padrões definidos socialmente que visam legitimar a exclusão. No 
entanto, a invisibilização se constitui como um processo, a nosso ver, ainda mais profundo de exclusão, que é a indiferença em relação ao outro, o não reconhecimento de sua existência ou de suas necessidades, um "apagamento" social.

Nessa perspectiva, é possível identificar a invisibilidade das crianças imigrantes quando se sabe que elas existem, uma vez que há estatísticas que comprovam sua existência, no entanto os dados não revelam suas condições concretas de vida e as possíveis violações de direitos a que estão sujeitas. Do mesmo modo, há matrículas que comprovam que elas fazem parte do município, de uma comunidade escolar, embora não sejam delineadas políticas e propostas educativas que considerem suas especificidades. Enfim, elas estão nas salas de aula, mas nas práticas pedagógicas encontramos uma proposta que visa a assimilação da língua portuguesa como passaporte para a aprendizagem, um silenciamento de suas culturas e dos conhecimentos que as constituem.

Podemos dizer que, se no contexto educativo a invisibilidade se expressa em práticas pedagógicas que anulam as demandas e necessidades das crianças imigrantes, entendemos que é a partir desse cotidiano e das práticas nele desenvolvidas que se pode viabilizar propostas que promovam o reconhecimento e o diálogo com as diferenças e a diversidade. Candau (2010, p. 53) faz uma constatação:

\begin{abstract}
Parece que o sistema público de ensino, nascido no contexto da modernidade, assentado no ideal de uma escola básica a que todos têm direito e que garanta o acesso a todos dos conhecimentos sistematizazados de caráter considerado "universal", além de estar longe de garantir a democratização efetiva do direito à educação e ao conhecimento sistematizado, terminou por criar uma cultura escolar padronizada, ritualística, formal, pouco dinâmica [...].
\end{abstract}

Candau (2010), ao falar dos sistemas de ensino, afirma que a escola, assim como a sociedade, constitui-se na multiculturalidade, ou seja, o reconhecimento da diversidade cultural presente na sociedade se reflete nas culturas presentes na escola. Reconhecer essa diversidade é um passo para promover o diálogo, o respeito e a tolerância nesse cotidiano.

Em nosso trabalho, abordamos o multiculturalismo enquanto uma realidade social, ou seja, compreendemos que a sociedade é composta por vários grupos étnicoculturais, que interagem e compartilham suas diferenças, ora reafirmando suas identidades, ora criando novas culturas. O diálogo entre esses diferentes grupos favorece o interculturalismo, ou seja, a inter-relação, o diálogo e a apropriação cultural entre diversas culturas. Para Candau (2010, p. 56), essa perspectiva "orienta processos que têm por base o reconhecimento do direito à diversidade e a luta contra todas as formas de discriminação e desigualdade social e tentam promover relações dialógicas e igualitárias entre pessoas e grupos".

Ao pensarmos a sociedade e a escola na perspectiva do multiculturalismo, torna-se possível problematizar as relações que envolvem as práticas desenvolvidas em seus cotidianos. A educação, nessa perspectiva multicultural, considera que a diversidade não pode apenas ser reconhecida, deve também ser valorizada e 
PEROZA, M. A. de R.; SANTOS, N. M. dos.

compartilhada nos diversos movimentos da escola. Nesse sentido, cabe às instituições educativas promover uma proposta intercultural, ou seja, um diálogo respeitoso entre as diversas manifestações culturais que existem no ambiente escolar. De acordo com Candau (2010, p. 59), a educação intercultural se constitui em "um enfoque global que deve afetar a cultura escolar e a cultura da escola como um todo, a todos os atores e a todas as dimensões do processo educativo, assim como a cada uma das escolas e ao sistema de ensino como um todo". Essa perspectiva nos convida a refletir sobre a escola da atualidade, além de traçar novos rumos para a escola que queremos no futuro.

Tomando por base esses conceitos e compreensões, passamos a analisar como essas concepções se evidenciam nos dados da pesquisa e que nos levou a constatar processos de invisibilidade no cotidiano das escolas da rede municipal de Ponta Grossa.

CONSIDERAÇÕES SOBRE OS PROCESSOS DE INVISIBILIZAÇÃO DAS CRIANÇAS IMIGRANTES NA REDE PÚBLICA DE ENSINO DE PONTA GROSSA

O estudo aqui apresentado, no decorrer de sua realização, foi apontando uma série de elementos que desvelavam os processos de invisibilização das crianças imigrantes no contexto educacional. A invisibilidade da criança nos processos migratórios se anunciou já no princípio do estudo. A revisão de literatura havia apontado a escassez de pesquisas sobre e com as crianças imigrantes e seus modos de viver a infância. No entanto, essa perspectiva se confirmou mais fortemente quando, na busca pelos dados junto à SME, nos informaram que não havia informações sobre o número de crianças imigrantes matriculadas na rede. Essa constatação acabou por mobilizar a secretaria a buscar e sistematizar essas informações e identificar tanto as crianças quanto as escolas que as atendiam, indicando a necessidade de um acompanhamento pedagógico mais específico.

O município de Ponta Grossa, em 2019, atendia cerca de 31 mil crianças da Educação Infantil ao $5^{\circ}$ ano do Ensino Fundamental. No levantamento realizado junto à SME, naquele ano, havia 32 crianças imigrantes matriculadas na rede, sendo 9 na Educação Infantil e 23 nos anos iniciais do Ensino Fundamental. Essas crianças estavam distribuídas em 19 escolas, sendo 4 CMEls e 15 escolas de Ensino Fundamental, localizadas em 16 bairros da cidade.

Ainda que, proporcionalmente, o número de crianças imigrantes seja pequeno, é um número expressivo se considerarmos os desafios que se colocam para essas crianças e suas famílias em relação à garantia de direitos, assim como para as escolas que as recebem. Naquele cenário, 19 escolas da rede vivenciavam os desafios de considerar, nas práticas pedagógicas, o atendimento às especificidades dos processos educativos com crianças imigrantes.

Das crianças atendidas na Educação Infantil, 2 estavam na etapa da creche, 7 frequentavam a pré-escola, inseridas em 4 CMEls, e 3 frequentavam turmas de préescola em escolas de Ensino Fundamental. Aqui, cabe destacar que a matrícula é compulsória a partir dos 4 anos de idade (BRASIL, 1996), o que significa que há muitas crianças de 0 a 3 anos não matriculadas na creche em virtude da não obrigatoriedade e/ou da escassez de vagas para esta faixa etária.

Buscando caracterizar as crianças, os dados evidenciavam que, do total de 32 crianças, uma parte significativa era de língua espanhola, sendo 15 advindas de países 
latino-americanos. Os dados apresentam correlação com aqueles divulgados nos relatórios oficiais que apontam um contingente maior de imigrantes advindos de países do sul global, marcadamente, venezuelanos e haitianos, em decorrência das correntes migratórias mais expressivas que chegaram no Brasil na última década.

As evidências iniciais nos levaram a aprofundar o estudo no sentido de conhecer como ocorriam os processos educativos das crianças imigrantes na escola, os desafios enfrentados pelos profissionais e as propostas de atendimento às especificidades das crianças imigrantes. Para tanto, na impossibilidade de estarmos presencialmente na escola, encaminhamos os questionários aos profissionais por e-mail e, posteriormente, convidamos para uma etapa de entrevistas.

Neste texto, dentre os diversos aspectos tratados no questionário e nas entrevistas, optamos por discutir os desafios vivenciados na prática pedagógica e as estratégias encontradas para superar esses desafios, pois identificamos que guardam relação com a discussão sobre a invisibilidade da criança imigrante. As respostas expressas nos questionários indicam que os maiores desafios enfrentados pelos profissionais estão relacionados à língua e à comunicação com as crianças e suas famílias, assim como à falta de um acompanhamento intersetorial - para as famílias - e pedagógico para os professores.

De modo especial, as professoras relataram, como desafio, o processo de alfabetização das crianças, uma vez que, para aprender a língua portuguesa, as crianças precisariam se apropriar de nossa cultura. A professora que participou da entrevista respondeu que sua dificuldade era: "a comunicação, entre professora e aluno. $\mathrm{O}$ aprendizado do aluno por ele não entender muitas palavras ficando difícil sua alfabetização. Pois ele não tinha se alfabetizado nem no seu país" (PR1) ${ }^{3}$.

Para minimizar as dificuldades em estabelecer a comunicação com as crianças, nos questionários, os profissionais destacaram o uso de aplicativos de tradução, gestos para complementar a comunicação oral, cadernos com imagens impressas, assim como elaboração de projetos que valorizassem a cultura que as crianças traziam. A diretora entrevistada afirma que houve uma mobilização da comunidade escolar para atender às especificidades das crianças imigrantes atendidas na escola: "A necessidade fez a escola buscar caminhos, foi nossa primeira experiência em 2019 e sabíamos que a escola precisava inserir essa criança e ajudá-la a crescer intelectualmente e como pessoa mesmo estando nesse contexto totalmente diferente do seu" (D3) ${ }^{4}$.

No entanto, a maioria dos professores relatou encontrar dificuldades, na prática pedagógica de modo especial, em articular um trabalho significativo com as crianças imigrantes, que não dominam a língua portuguesa, sem deixar de atender o restante da turma, uma vez que precisam cumprir a proposta curricular sem prejudicar os demais alunos. Essa perspectiva é reafirmada nas entrevistas com uma professora e uma diretora que disseram ser necessário um apoio e um acompanhamento que ajudem a atender as crianças em suas necessidades pedagógicas. O quadro esboçado por elas demonstra os desafios de muitas salas de aula:

As crianças entram numa turma de trinta alunos, mais ou menos, que é a média, e aí a professora não conseguia dar atenção para essa criança e ao mesmo tempo tinha que ser feito diferenciado 
PEROZA, M. A. de R.; SANTOS, N. M. dos.

com ela, até para ela poder aprender, claro, na socialização, ela ia desenvolvendo o idioma, porém, questão de, da língua portuguesa, do trabalho com ela, precisava de alguém fazendo um outro trabalho individualizado (D1, 2020).

Então, acho que a pior parte ali foi a comunicação. Eu precisava ter o retorno dele. E então, às vezes, era uma classe que já tinha muita dificuldade, eu não podia focar só nele, eu não tinha auxiliar, então eu estava com uma turma de trinta alunos, todos com grandes dificuldades e eu precisava ir de carteira em carteira (PR1, 2020).

Percebe-se que, nas entrevistas, também, fica evidente a necessidade de um acompanhamento pedagógico que permita encontrar maneiras de ensinar os conteúdos, de possibilitar uma comunicação que assegure as aprendizagens de todas as crianças e, de modo específico, alfabetizar, ensinar a língua portuguesa àquelas crianças que não a dominam. No entanto, uma lacuna persiste na relação entre o professor e a criança imigrante que considera, mas vai além, a estrutura da sala de aula ou o esforço do professor: existe uma visão monocultural do processo educativo, persistem as propostas homogeneizadoras e que buscam o ensino da língua por parte do professor e da assimilação da língua pela criança como forma de introduzi-la na cultura local para, a partir daí, reconhecer que a aprendizagem acontece.

É possível identificar que, nos relatos sobre as dificuldades enfrentadas, há um entendimento de que a dificuldade em relação à língua é da criança imigrante, assim como aquelas relacionadas ao domínio da cultura "que não é dela", o que deixa claro a relação de poder dos nativos sobre as "debilidades" dos que chegam à "nossa cultura".

Nas respostas dos profissionais, tanto nos questionários quanto nas entrevistas, aparecem elementos que justificam essa análise. Como na resposta de uma das diretoras ao questionário: "eles têm dificuldade de entender esse novo espaço em um mundo que não pertence a eles, no entanto se esforçam para tentar driblar as dificuldades. A linguagem é seu maior desafio" (D3, 2020).

Percebe-se que a dificuldade é expressa como algo do sujeito imigrante, não do professor ou da equipe da escola, das outras crianças para compreender a linguagem e a cultura do outro. Essa resposta, assim como outras, esboça essa percepção de marginalização, de exclusão, de invisibilidade em duas vias: de um lado, o sujeito que, em virtude de suas diferenças, precisa se esforçar para ser incluído; por outro, a busca por não deixar que o restante da turma fique "prejudicado" devido ao tempo dedicado à inclusão da criança imigrante.

Aqui, destacamos que a escola, pela própria função social que possui (PARO, 2011), precisa reconhecer as demandas específicas e individuais daqueles que a constituem, proporcionando um trabalho que possibilite a valorização da diversidade na construção de conhecimentos. A linguagem é um elemento fundamental na acolhida e na inclusão da criança imigrante. Ao entendermos a escola como um lugar de encontro da diversidade, concordamos com Farias e colaboradores (2009, p. 47):

Noutros termos, a linguagem organiza nossa visão de mundo e nosso estar no mundo, quer sejamos portadores de necessidades especiais, quer sejamos portadores de outras necessidades, como seres humanos inconclusos que todos somos. É por meio dela que 
nos comunicamos, por isso é relevante estudá-la e compreender seu papel no cotidiano e nas interações sociais.

Ou seja, o domínio da língua, por si só, não possibilita o encontro das diferenças, a acolhida da diversidade e a possibilidade de desenvolvimento integral. Os autores ressaltam a linguagem como viabilizadora das relações e interações sociais, ou seja, um conjunto de elementos simbólicos que possibilita a comunicação, o afeto, a solidariedade, a partilha de conhecimentos que cada indivíduo traz para o grupo.

As respostas deixam antever poucas tentativas de estabelecer diálogos entre as diferentes culturas que permeiam o cotidiano escolar (GUSMÃO, 2000), de modo a permitir que as crianças imigrantes se sintam pertencentes àquele universo de diversidade da escola e não como "aquele que vem de fora" e adentra uma cultura "que não é dele". Nesse sentido, ao dizerem de suas práticas, os profissionais apontam para um trabalho centrado no domínio da língua portuguesa, na imposição de uma cultura local e no desconhecimento a respeito de uma proposta que possa sair de uma leitura monocultural da realidade e se pautar em uma perspectiva intercultural (CANDAU, 2010).

No entanto, há, por parte das crianças imigrantes e de suas famílias, um desejo e a necessidade de pertencerem, serem acolhidos e apoiados na busca por uma vida melhor. Há, também, esforços e o desejo, por parte dos profissionais, de promover uma educação significativa, ainda que não saibam como fazer. Isso foi evidenciado quando uma professora, ao falar das estratégias de aproximação entre ela, a turma e a criança imigrante, indica um trabalho na direção da interculturalidade, "quase a turma toda passou a pesquisar o país e a sua língua, com a interação da professora, para se comunicar com o aluno e criar a amizade e ajudá-lo a se sentir acolhido por eles. Os alunos juntamente com a professora aprenderam palavras básicas para se comunicar da melhor forma com ele" (PR1, 2020).

Compreendemos que existem práticas comprometidas com uma educação inclusiva, acolhedora e respeitosa, e que todo esforço dos professores e equipes pedagógicas é válido. No entanto, destacamos que muitas práticas revelam concepções construídas culturalmente e naturalizadas socialmente. Nesse caso, defendemos que uma formação inicial e continuada de professores, numa perspectiva multicultural e fundamentada no diálogo intercultural, pode contribuir para mudanças nas propostas educativas e, por conseguinte, tornar os processos educativos mais significativos para todas as crianças e, especialmente, acolhedor para as crianças imigrantes.

\section{CONCLUSÃO}

Os movimentos migratórios, na atualidade, têm revelado os dramas de milhares de pessoas que chegam ao nosso país em busca de melhores condições de vida. No interior desses fluxos migratórios, os dramas vivenciados pelas crianças acabam por serem ignorados, constituindo-se no que aqui nomeamos como invisibilidade. Se no cenário mais amplo dessa realidade a criança imigrante segue desconsiderada, nos contextos escolares essa constatação pode ser reafirmada. 
PEROZA, M. A. de R.; SANTOS, N. M. dos.

Nesse sentido, este estudo buscou trazer elementos para compreender como a invisibilidade das crianças imigrantes expressas nos dados oficiais e nas políticas educacionais acabam por revelar um processo de invisibilização no âmbito da escola. Para tanto, desenvolvemos a pesquisa no município de Ponta Grossa/PR junto a profissionais de algumas escolas que receberam crianças imigrantes, para conhecer os desafios que os profissionais da escola vivenciam cotidianamente em suas práticas pedagógicas.

As análises realizadas evidenciam que as crianças imigrantes vivenciam um processo de invisibilização que se expressa em diferentes instâncias. Aqui, destacamos a insuficiência de dados sobre suas condições de vida nos relatórios oficiais, o que dificulta a elaboração de políticas públicas e de acesso aos direitos; a escassez de pesquisas que tomam a situação da criança imigrante nos fluxos migratórios e que a envolvam como participantes ativas dos estudos; e, por fim, no percurso da pesquisa, a invisibilidade se apresentou na ausência de dados na gestão municipal, o que nos indicava que elas poderiam estar sendo invisibilizadas no interior das escolas, das salas de aula, incorrendo na ampliação dos desafios para os professores e equipes pedagógicas em considera-las nas práticas educativas.

Entendemos que, em um contexto plural, a escola não pode ser um lugar da homogeneidade, uma vez que ela representa em si a própria sociedade, em todas as suas nuances. Ela se constitui como um espaço de diversidades, um lugar em que todas as pessoas precisam se sentir pertencentes à comunidade. No entanto, as práticas educativas desenvolvidas nas escolas, por vezes, estão fundamentadas em uma visão homogeneizadora da realidade que busca um padrão inexistente naquele contexto.

Destacamos que os profissionais que atendem crianças imigrantes possuem pouco conhecimento sobre a temática e não recebem um acompanhamento pedagógico que permita a eles redimensionar suas práticas numa perspectiva que dialogue com as múltiplas culturas e favoreça a interculturalidade. Portanto, os dados analisados, em certa medida, indicam a necessidade de os cursos de formação inicial e continuada tratarem da educação inclusiva e da diversidade como forma de favorecer a elaboração de propostas pautadas na interculturalidade. Essa estratégia pode possibilitar que os professores tenham elementos para trabalhar com a diversidade e que as crianças possam aprender na convivência e na partilha de conhecimentos e de cultura.

Artigo recebido em: 05/03/2021

Aprovado para publicação em: 28/05/2021

THE INVISIBILITY OF IMMIGRANT CHILDREN IN THE EDUCATIONAL ASSISTANCE OF THE PUBLIC EDUCATION SISTEM IN PONTA GROSSA/PR

ABSTRACT: Within migratory flows, children are not only the most vulnerable group in terms of violation of rights, but also the group with less visibility concerning their displacement. With the increase of immigration in Brazil, it was noticed a significant number of immigrant children in the 
public school system in Ponta Grossa/PR. This motivated studies whose results are discussed in the this paper. The aim of this article is to present an analysis of the invisibility of immigrant children and its impacts on educational assistance in the aforementioned educational network. The qualitative research used as methodological strategies questionnaires and semi structured interviews. The study demonstrated that children invisibility also appears on public educational policies as well as on the pedagogical practices carried out in schools.

KEYWORDS: Immigrant Children. Education. Pedagogical Practice. Invisibility.

\section{LA INVISIBILIDAD DE LOS NIÑOS INMIGRANTES EN LA ATENCIÓN EDUCATIVA DE LA RED DE EDUCACIÓN PÚBLICA DE PONTA GROSSA/PR}

RESUMEN: Al interior de los flujos migratorios, la niñez es uno de los grupos más vulnerables a las violaciones de derechos, y con menor visibilidad hacia su condición en el desplazamiento. Acompañando al aumento de la inmigración en Brasil, se constató, también, la presencia de un número significativo de niños inmigrantes en el sistema de escuelas públicas do municipio de Ponta Grossa/PR, lo que desencadenó la realización del estudio cuyos resultados parciales traemos en este texto. El objetivo de este artículo es presentar un análisis sobre la invisibilidad de estos niños, y sus reflejos en la asistencia educativa en esa red escolar. La investigación cualitativa tuvo como estrategias metodológicas el cuestionario y la entrevista semiestructurada. El estudio concluye que esta invisibilidad de los niños se refleja tanto en las políticas públicas de educación, como en las prácticas pedagógicas desarrolladas en la escuela.

PALABRAS CLAVE: Niños Inmigrantes. Educación. Práctica Pedagógica. Invisibilidad.

\section{NOTAS}

1) Projeto de pesquisa analisado e aprovado pelo Comitê de Ética na Pesquisa (CEP/UEPG) no. 2.991.263 de 30/10/2018 e autorizado pela Secretaria Municipal de Educação de Ponta Grossa.

2) Os participantes tiveram sua identidade preservada, sendo identificados com as iniciais de suas funções seguida da ordem de respostas recebidas. Neste caso, trata-se da Professora, respondente 1.

3) Trata-se da Diretora, respondente 3.

\section{REFERÊNCIAS}

ACNUR. Perfil socioeconômico dos refugiados no Brasil: subsídios para elaboração de políticas. 2019. Disponível em <https://www.acnur.org/portugues/wpcontent/uploads/2019/05/Resumo-Executivo-Versa\%CC\%83o-Online.pdf>. Acesso em: $15 \mathrm{fev}$. de 2021. 
PEROZA, M. A. de R.; SANTOS, N. M. dos.

ARIÈS, P. História Social da criança e da família. Tradução de Dora Flaksman. 2. ed. Rio de Janeiro: LTC, 2006.

BRASIL. Ministério da Educação. Lei de Diretrizes e Bases da Educação Nacional. Lei n.9394/96. Brasília, DF: MEC/SEF, 1996.

BRASIL, Ministério da Justiça. Lei de Migração. Lei n. 13.445, maio/2017. Brasília, 2017. CAMBI, F. História da Pedagogia. Tradução de Álvaro Lorencini. São Paulo: Fundação Editora UNESP, 1999.

CANDAU, V. M. F. Sociedade, cotidiano escolar e cultura(s): uma aproximação. Educação \& Sociedade, Campinas, n. 79, p. 125-162, ago. 2002.

CASTRO, M. G. Migrações internacionais e direitos humanos e o aporte do reconhecimento. REMHU - Revista Interdisciplinar da Mobilidade Humana, Brasília, v. 16, n. 31, p. 7-36, 2008. Disponível em: $<$ https://www.redalyc.org/pdf/4070/407042009002.pdf $>$. Acesso em: 18 de abr. de 2020.

CAVALCANTI, L.; BOTEGA, T.; TONHATI, T.; ARAÚJO, D. Dicionário crítico de migrações internacionais (Locais do Kindle 30). SciELO - Editora UnB. Edição do Kindle. Brasília: Editora Universidade de Brasília, 2017. E-3788 Kb; ePUB.

CAVALCANTI, L.; OLIVEIRA, T.; MACEDO, M. Imigração e refúgio no Brasil. In: Relatório anual, 2020. Série Migrações. Observatório das Migrações Internacionais; Ministério da Justiça e Segurança Pública/ Conselho Nacional de Imigração e Coordenação Geral de Imigração Laboral. Brasília, DF: OBMigra, 2020. Disponível em: $<$ https://portaldeimigracao.mj.gov.br/images/dados/relatorioanual/2020/OBMigra_RELAT\%C3\%93RIO_ANUAL_2020.pdf $>$. Acesso em: 15 de fev. 2021.

COLARES, E. S. Entre ir, (não) chegar e (não) voltar: as dinâmicas dos deslocamentos forçados de crianças centro-americanas e mexicanas aos Estados Unidos. 2019. Tese (Doutorado em Ciências Sociais) - programa de doutorado, UnB, Brasília, 2019. Disponível em: <https://repositorio.unb.br/handle/10482/35199>. Acesso em: $30 \mathrm{de}$ maio de 2021.

DALLARI, D. A.; KORCZAK, J. O direito da criança ao respeito. São Paulo, Summus, 1986. FARIAS, I. R.; SANTOS, A. F.; SILVA, E. B. da. Reflexões sobre a inclusão linguística no contexto escolas. In: DÍAZ, F., et al, orgs. Educação inclusiva, deficiência e contexto social: questões contemporâneas [online]. Salvador: EDUFBA, 2009, pp. 39-48. Disponível em: <http://books.scielo.org/id/rp6gk/pdf/diaz-9788523209285-04.pdf >. Acesso em: 15 ago. 2021.

FELDMAN-BIANCO, B. Apresentação: deslocamentos, desigualdades e violência do Estado. Revista Ciência e Cultura, São Paulo, v.67 n. 2, abr./jun. 2015. Disponível em: 
$<$ http://cienciaecultura.bvs.br/scielo.php?script=sci_arttext\&pid=S0009-

67252015000200009 >. Acesso em: 17 de março de 2020.

GUSMÃO, N. M. M.; Desafios da diversidade na escola. Revista Mediações, Londrina, v.5, n.2, p. 9-28. Jul/Dez. 2000.

GRAJZER, D. E. Crianças refugiadas: um olhar para a infância e seus direitos. 2018. Dissertação (Mestrado em Educação) - Universidade Federal de Santa Catarina, Florianópolis, 2018.

KRAMER, S.; LEITE, M. I. (Org.). Infância: fios e desafios da pesquisa. Campinas/SP: Papirus, 2015.

MACHADO, L. M. As crianças refugiadas e seu direito fundamental à educação. 2017. 56 f. Trabalho de Conclusão de Curso (Especialização em Direito Internacional Público e Privado e Direito da Integração) - Universidade Federal do Rio Grande do Sul, Porto Alegre, 2017.

MARTINS, J. S. A sociedade vista do abismo: novos estudos sobre exclusão social, pobreza e classes sociais. 2a ed. Petrópolis, RJ: Vozes, 2002.

MILESI, R.; Refugiados e migrações forçadas: uma reflexão aos 20 anos da declaração de Cartagena. Ed. Ministério da Justiça. 10p. 2005. Disponível em: <http://portal.mj.gov.br/main.asp?Team=\%7BC728A416-5AA7-476D-B239

CC89FFB36301\%7D>. Acesso em: dez. de 2019.

OIM. Informe sobre las migraciones en el mundo 2020. Capítulo 8: Los niños y la migración insegura. 2020.2 Disponível em: $<$ https://publications.iom.int/system/files/pdf/wmr_2020_es_ch_8.pdf $>$. Acesso em: 25 de abr. 2020.

OLIVEIRA, C.; KÖHLER. N. S. A insuficiência do sistema de proteção destinado às crianças migrantes e refugiadas diante da dupla vulnerabilidade que as acomete. In: XVI Seminário Internacional: Demandas Sociais e Políticas Públicas na Sociedade Contemporânea, Universidade de Santa Cruz do Sul, 2019.

ONU. Convenção sobre os direitos da criança, 1989. Disponível em https://www.unicef.org/brazil/convencao-sobre-os-direitos-da-crianca Acesso em 07 de abr. 2020.

PARO, V. H. O currículo do ensino fundamental como tema de política pública: a cultura como conteúdo central. Ensaio: Avaliação Políticas Públicas Educacionais, Rio de Janeiro, v. 19, n. 72 , p. 485-508, jul./set., 2011. Disponível em: 
PEROZA, M. A. de R.; SANTOS, N. M. dos.

$<$ https://www.scielo.br/pdf/ensaio/v19n72/a03v19n72.pdf $>$. Acesso em: 15 de fevereiro de 2020.

PEROZA, M. A. R. Infância, educação e dignidade humana: considerações sobre os processos educativos da criança. Práxis Educativa, Ponta Grossa, Ahead of Print, v. 13, n. 1, jan./abr. $2018 . \quad$ Disponível em: $<$ https://www.revistas2.uepg.br/index.php/praxiseducativa/article/view/10552/6145>. Acesso em: 13 de mar. 2020.

RIFIOTIS, F. C. Tecnologias de governo e imigração internacional: pistas para pensar as experiências das crianças em situação de refúgio no Brasil. Revista de Estudos Empíricos em Direito, São Paulo, v. 5, n. 3, p. 257-267, dez. 2018. Disponível em: $<$ https://reedrevista.org/reed/article/view/383/pdf > . Acesso em: 13 de abril de 2020.

ROUSSEAU. J. J. Emílio ou da Educação. Tradução de Roberto Leal Ferreira. São Paulo: Martins Fontes, 2014.

SARMENTO, M. J. A sociologia da infância e a sociedade contemporânea: desafios conceituais e praxeológicos. In: ENS, R. T.; GARANHANI, M. C. A sociologia da infância e a formação de professores. Curitiba: Champagnat, 2013.

SOARES, N. F. Os Direitos das Crianças nas encruzilhadas da Proteção e da Participação. Revista Zero-a-seis, Florianópolis, v. 7, n. 12, 2005. Disponível em: $<$ https://periodicos.ufsc.br/index.php/zeroseis/article/view/2100 >. Acesso em: 5 de abr. 2020.

TEIXEIRA, M. C. "Mas podia ter coentro": crianças migrantes e trajetórias que se encontram. 2018. 156 f. Tese (Doutorado em Educação) - Universidade Federal de Juiz de Fora, Juiz de Fora, 2018.

TOMÁS, J. C. de S. P. A invisibilidade social, uma perspectiva fenomenológica. In: VI Congresso Português de Sociologia - Mundos sociais: saberes e práticas, Universidade Nova de Lisboa, 25 a 25 de junho de 2008. Disponível em: $<$ http://associacaoportuguesasociologia.pt/vicongresso/pdfs/285.pdf $>$. Acesso em: 23 de fev. 2021.

\footnotetext{
Marilúcia AntônIa de Resende Peroza: Graduada em Pedagogia pela Universidade do Estado de Minas Gerais (2001), mestra em Educação pela Pontifícia Universidade Católica do Paraná (2012) e doutora em Educação pela Pontifícia Universidade Católica do Paraná (2017). Atualmente é professora Adjunta na Universidade Estadual de Ponta Grossa, atuando no curso de Pedagogia e no Programa de Pós-graduação em Educação PPGE/UEPG.

Orcid: https://orcid.org/0000-0002-2733-5244

E-mail:malu.ueps@smail.com
} 
Natálla Mendes dos SANTOS: Graduada em Pedagogia pela Universidade Estadual de Ponta Grossa. Professora de Educação Infantil na rede privada de ensino de Ponta Grossa.

Orcid: https://orcid.org/0000-0002-9924-2987

E-mail: nataliamendes1410@outlook.com

Este periódico utiliza a licença Creative Commons Attribution 3.0, para periódicos de acesso aberto (Open Archives Initiative - OAI). 